\title{
openheart A pragmatic approach to risk assessment in pulmonary arterial hypertension using the 2015 European Society of Cardiology/European Respiratory Society guidelines
}

\author{
Fabio Dardi (D) , ${ }^{1}$ Alessandra Manes, ${ }^{2}$ Daniele Guarino, ${ }^{1}$ Elisa Zuffa, ${ }^{1}$ \\ Alessandro De Lorenzis, ${ }^{1}$ Ilenia Magnani, ${ }^{1}$ Mariangela Rotunno, ${ }^{1}$ Alberto Ballerini, ${ }^{1}$ \\ Gerardo Vito Lo Russo, ${ }^{1}$ Elena Nardi (1) , ${ }^{1}$ Nazzareno Galiè, ${ }^{1}$ \\ Massimiliano Palazzini ${ }^{1}$
}

\begin{abstract}
- Additional supplemental material is published online only. To view, please visit the journal online (http://dx.doi.org/10. 1136/openhrt-2021-001725)

To cite: Dardi F, Manes A, Guarino D, et al. A pragmatic approach to risk assessment in pulmonary arterial hypertension using the 2015 European Society of Cardiology/European Respiratory Society guidelines. Open Heart 2021;8:e001725. doi:10.1136/

openhrt-2021-001725
\end{abstract}

FD and AM are joint first authors.

NG and MP are joint senior authors.

Received 18 May 2021 Accepted 7 September 2021

Check for updates

(C) Author(s) (or their employer(s)) 2021. Re-use permitted under CC BY-NC. No commercial re-use. See rights and permissions. Published by BMJ.

${ }^{1}$ Department of Experimental, Diagnostic and Specialty Medicine - DIMES, University of Bologna, Bologna, Italy ${ }^{2}$ Cardio-Thoracic-Vascular Department, IRCCS Sant'Orsola University Hospital, Bologna, Italy

Correspondence to Dr Fabio Dardi; fabio.dardi2@ unibo.it

\section{ABSTRACT}

Objective To optimise treatment of patients with pulmonary arterial hypertension (PAH), the 2015 European Society of Cardiology/European Respiratory Society guidelines recommend using risk stratification, with the aim of patients achieving low-risk status. Previous analyses of registries made progress in using risk stratification approaches, however, the focus is often on patients with a low-risk prognosis, whereas most PAH patients are in intermediate-risk or high-risk categories. Using only six parameters with high prognostic relevance, we aimed to demonstrate a pragmatic approach to individual patient risk assessment to discriminate between patients at low risk, intermediate risk and high risk of death.

Methods Risk assessment was performed combining six parameters in four criteria: (1) WHO functional class, (2) 6 min walk distance, (3) N-terminal pro-brain natriuretic peptide (BNP)/BNP plasma levels or right atrial pressure and (4) cardiac index or mixed venous oxygen saturation. Assessments were made at baseline and at first follow-up after 3-4 months.

Results 725 PAH treatment-naive patients were analysed. Survival estimates between risk groups were statistically significant at baseline and first follow-up $(p<0.001)$, even when the analysis was performed within PAH etiological subgroups. Similar results were observed in 208 previously treated PAH patients. Furthermore, patients who remained at or improved to low risk had a significantly better estimated survival compared with patients who remained at or worsened to intermediate risk or high risk $(\mathrm{p} \leq 0.005)$

Conclusion The simplified risk-assessment method can discriminate idiopathic, connective-tissue-diseaseassociated and congenital-heart-disease-associated $\mathrm{PAH}$ patients into meaningful high-risk, intermediate-risk and low-risk groups at baseline and first follow-up. This pragmatic approach reinforces targeting a low-risk profile for PAH patients.

\section{Key questions}

What is already known about this subject?

- Current pulmonary arterial hypertension guidelines recommend to assess the risk profile and to achieve a low-risk status in all patients. Different risk stratification approaches have been proposed based on previous analyses of registries. However, the methodology of these analyses is either not easy-to-use at the bedside or incomplete.

What does this study add?

- A pragmatic and easy-to-use approach with only six highly prognostic relevant parameters (functional class, 6 min walking distance, brain natriuretic peptides plasma levels, right atrial pressure, cardiac index and mixed venous oxygen saturation) is able to well discriminate among patients at low, intermediate and high risk of death.

How might this impact on clinical practice?

- The proposed simplified risk stratification tool may favour current guidelines application in clinical practice and may be useful in clearly distinguish, besides the low-risk profile, patients that are at intermediate risk versus high risk. Indeed, because of their different prognosis, the two latter categories of patients should receive a different treatment intensity.

\section{INTRODUCTION}

Pulmonary arterial hypertension $(\mathrm{PAH})$ is a rare disease characterised by remodelling of the distal pulmonary vasculature and is ultimately fatal. ${ }^{12}$ Over the past two decades, numerous randomised controlled trials have been performed, leading to the approval of compounds acting on three pathways of PAH pathobiology. ${ }^{12}$ The ability to target the nitric oxide, endothelin and prostacyclin pathways has allowed the development of 
tailored treatment approaches, ${ }^{12}$ resulting in improved patient outcomes. ${ }^{34}$ Despite these advances, prognosis remains poor for patients with PAH. In order to optimise patient management, the current 2015 European Society of Cardiology (ESC)/European Respiratory Society (ERS) PH Guidelines advocate for an approach that includes multiparametric risk stratification where patients are classified based on their disease severity. In this approach, prognostic clinical, exercise, biochemical, imaging and haemodynamic parameters are used to characterise patients as low risk, intermediate risk or high risk according to 1-year risk of mortality. ${ }^{12}$ The parameters were derived from observational research including the French registry risk equation ${ }^{5}$ and the Registry to Evaluate Early and Long-term PAH Disease Managment (REVEAL) risk score. ${ }^{6-9}$ In addition, the specific thresholds employed are supported by post hoc analyses of recent large randomised controlled trials. ${ }^{10-12}$

Risk stratification in PAH patients based on the prognostic parameters outlined in the 2015 ESC/ERS PH guidelines has been validated recently in three European registries. ${ }^{13-17}$ These analyses showed that PAH patients could be stratified into different mortality-risk groups at baseline and at first follow-up using a number of the prognostic parameters described in the guidelines. ${ }^{13-16}$ For each registry, there were differences in the patients evaluated, the prognostic parameters considered, and the specific methods used to stratify patients. The Swedish and the Comparative, Prospective Registry of Newly Initiated Therapies for Pulmonary Hypertension (COMPERA) registries assessed cohorts of newly diagnosed PAH patients comprising idiopathic PAH (IPAH), connective-tissue-disease-associated PAH (CTD-PAH) and congenital-heart-disease-associated-PAH (CHD-PAH) ${ }^{14} 15$ These registries assigned scores for low $($ score $=1)$, intermediate (score $=2$ ) and high $($ score $=3$ ) risk of 1 -year mortality by calculating the mean score for up to eight parameters. ${ }^{14-16}$ The limitation of this approach in evaluating the individual risk profile is based on the arbitrary attribution of the same scores to all the variables and on the final average value, which may be the result of parameters from all risks groups; moreover it is not a simple tool to use at the patient's bedside without a calculator. The French Pulmonary Hypertension Registry (FPHR) stratified IPAH ${ }^{13}$ and CTD-PAH ${ }^{16}$ patients based on the number of low-risk criteria present. A greater number of low risk criteria, $0-4$ or $0-3$ depending on the parameters assessed, was indicative of lower mortality risk. ${ }^{13} 16$ The use of few parameters is attractive and the focus on low risk is aspirational, however, applying this approach in clinical practice may be problematic as the majority of PAH patients are unfortunately at intermediate risk and it may be important to differentiate these patients from the high-risk patients.

We performed retrospective analyses in a prospective PAH patient registry and included assessment of the overall $\mathrm{PAH}$ population, as well as assessment within specific aetiologies, including CTD-PAH and CHD-PAH. Patients were treated according to ESC/ERS PH guidelines. ${ }^{12}$ 18-20 The purpose of our study was to evaluate whether a pragmatic approach based on four criteria could be used to differentiate between patients with low risk, intermediate risk and high risk of death. Our approach is based on the six parameters with highest prognostic relevance as assessed in recent registry analyse ${ }^{13-16}$ : WHO functional class (WHO FC), 6 min walk distance (6MWD), N-terminal pro-brain natriuretic peptide (NT-pro-BNP)/BNP or right atrial pressure (RAP) and cardiac index (CI) or mixed venous oxygen saturation $\left(\mathrm{SvO}_{2}\right)$.

\section{METHODS \\ Study population}

The study complies with the Declaration of Helsinki. ${ }^{21}$ Patient data were pseudonymised and the patients, or their legally authorised representative, provided written informed consent for their use.

PAH was diagnosed according to ESC/ERS PH guidelines. ${ }^{12}{ }^{18-20}$ Consecutive patients with a diagnosis of idiopathic/heritable/drug-induced PAH (IPAH/HPAH/ DPAH), CTD-PAH and CHD-PAH were included in the analysis. The observation period was from February 2003 to December 2017. All patients underwent clinical (WHO $\mathrm{FC}$ ), exercise (6MWD), biochemical (NT-pro-BNP or BNP plasma levels) and haemodynamic (CI, RAP, $\mathrm{SvO}_{2}$ ) assessments at baseline. Haemodynamic assessments were carried out via right heart catheterisation. All patients with a positive response to acute vasodilator challenge were treated with calcium channel blockers. Patients who were naive to $\mathrm{PAH}$ therapy at baseline evaluation were treated according to ESC/ERS PH guidelines ${ }^{12-20}$ and underwent a complete re-assessment 3-4 months after the baseline evaluation. PAH specific sequential combination therapy was indicated according to a goal-oriented treatment strategy if treatment goals were not met. ${ }^{22}$

\section{Risk stratification}

Risk assessment was performed according to a simplified and practical version of the 2015 ESC/ERS PH risk stratification strategy including the parameters with predictive value used and validated in the recent studies. ${ }^{13-15}$

The risk evaluation was based on four criteria including six parameters (table 1): clinical (WHO FC), exercise (6MWD), biochemical (NT-pro-BNP or BNP plasma levels) and haemodynamic (CI, RAP, $\mathrm{SvO}_{2}$ ).

The risk stratification strategy did not necessarily require results for all six of these parameters as NT-pro-BNP/ BNP plasma levels and RAP could be considered as being alternatives for the same criterium ${ }^{23}$ as could CI and $\mathrm{SvO}_{2}$ (table 1). ${ }^{24}$ Despite its arbitrariness we think that this can be considered a reasonable approach as we not only determined a correlation between RAP and both BNP $(\mathrm{r}=0.499, \mathrm{p}<0.001)$ and NT-pro-BNP $(\mathrm{r}=0.381$, $\mathrm{p}<0.001)$ and between CI and $\mathrm{SvO} 2(\mathrm{r}=0.505, \mathrm{p}<0.001)$, but also because the two pairings of parameters share similar pathophysiologic and prognostic information 


\begin{tabular}{|c|c|c|c|c|}
\hline $\begin{array}{l}\text { Risk } \\
\text { criteria }\end{array}$ & $\begin{array}{l}\text { Determinants of prognosis* } \\
\text { (estimated 1-year mortality) }\end{array}$ & $\begin{array}{l}\text { Low risk variables } \\
(<5 \%)\end{array}$ & $\begin{array}{l}\text { Intermediate risk variables } \\
(5 \%-10 \%)\end{array}$ & $\begin{array}{l}\text { High risk variables } \\
(>10 \%)\end{array}$ \\
\hline A. & WHO functional class & I, II & III & IV \\
\hline B. & 6MWD & $>440 \mathrm{~m}$ & $165-440 \mathrm{~m}$ & $<165 m$ \\
\hline C. & $\begin{array}{l}\text { NT-pro-BNP/BNP plasma levels or } \\
\text { RAP }\end{array}$ & $\begin{array}{l}\mathrm{BNP}<50 \mathrm{ng} / \mathrm{L} \\
\text { NT-pro-BNP }<300 \mathrm{ng} / \mathrm{L} \text { or } \\
\mathrm{RAP}<8 \mathrm{~mm} \mathrm{Hg}\end{array}$ & $\begin{array}{l}\text { BNP } 50-300 \mathrm{ng} / \mathrm{L} \\
\text { NT-pro-BNP } 300-1400 \mathrm{ng} / \mathrm{L} \text { or } \\
\text { RAP } 8-14 \mathrm{~mm} \mathrm{Hg}\end{array}$ & $\begin{array}{l}\text { BNP }>300 \mathrm{ng} / \mathrm{L} \\
\text { NT-pro-BNP }>1400 \mathrm{ng} / \mathrm{L} \text { or } \\
\text { RAP }>14 \mathrm{~mm} \mathrm{Hg}\end{array}$ \\
\hline D. & $\begin{array}{l}\mathrm{Cl} \text { or } \\
\mathrm{SvO}_{2}\end{array}$ & $\begin{array}{l}\mathrm{Cl} \geq 2.5 \mathrm{~L} / \mathrm{min} / \mathrm{m}^{2} \\
\text { or } \\
\mathrm{SvO}_{2}>65 \%\end{array}$ & $\begin{array}{l}\mathrm{Cl} 2.0 \text { to } 2.4 \mathrm{~L} / \mathrm{min} / \mathrm{m}^{2} \\
\text { or } \\
\mathrm{SvO}_{2} 60 \%-65 \%\end{array}$ & $\begin{array}{l}\mathrm{Cl}<2.0 \mathrm{~L} / \mathrm{min} / \mathrm{m}^{2} \\
\text { or } \\
\mathrm{SvO}_{2}<60 \%\end{array}$ \\
\hline \multicolumn{2}{|c|}{ Individual risk category definition } & $\begin{array}{l}\text { Low-risk definition } \\
\text { At least three low-risk criteria } \\
\text { and no high-risk criteria }\end{array}$ & $\begin{array}{l}\text { Intermediate-risk definition } \\
\text { Definitions of low or high risk not } \\
\text { fulfilled }\end{array}$ & $\begin{array}{l}\text { High-risk definition } \\
\text { At least two high-risk criteria } \\
\text { including } \mathrm{Cl} \text { or } \mathrm{SvO}_{2}\end{array}$ \\
\hline
\end{tabular}

${ }^{*}$ Most of these variables have been validated mostly for IPAH and the cut-off levels used above may not necessarily apply to other forms of $\mathrm{PAH}$.

BNP, brain natriuretic peptide; CI, cardiac index; IPAH, idiopathic PAH; 6MWD, 6 min walk distance; NT-pro-BNP, N-terminal pro-brain natriuretic peptide; $\mathrm{PAH}$, pulmonary arterial hypertension; RAP, right atrial pressure; SvO2, mixed venous oxygen saturation; WHO, World Health Organization.

and, in both cases, if both parameters in each pairing (ie, NT-pro-BNP/BNP plasma levels and RAP; CI and SvO2) were available, we chose the parameter with the worse prognostic value to avoid potential risk underestimation.

As set out in table 1, results from the parameter assessments were used to stratify patients at low, intermediate or high risk of death. Patients considered to be at low risk were those who had at least three parameters with low-risk assessment and none with high-risk assessment; those patients at high-risk had $\mathrm{CI}$ or $\mathrm{SvO}_{2}$ and one other criterion with high-risk assessments; intermediate-risk patients were those that did not meet the above requirements for low or high risk.

Risk stratification was assessed at baseline with the first follow-up assessment undertaken 3-4months after the baseline evaluation. As exploratory analyses, we examined the number of patients that could not be designated at low-risk despite permissive 3 low-risk criteria due to concurrent one high-risk criterion.

\section{Statistics}

Continuous variables were expressed as median (IQR) and categorical variables as $\mathrm{n}(\%)$. Data comparisons were made with Wilcoxon-Mann-Whitney test. Correlations were tested with Pearson correlation coefficient. Survival was displayed using Kaplan-Meier plots and the difference between subgroups tested for significance using the log-rank test. HRs for pairwise comparisons between risk-categories were estimated using Cox regression analysis. HRs for the single risk-score items were estimated with Cox regression analysis, using the respective low-risk group as reference. All-cause death was considered and patients were censored as alive at the time of lung transplantation. Survival was evaluated from baseline evaluation in our centre, rather than from diagnosis of PAH, to avoid immortal time bias. ${ }^{25}$
The c-statistic was used to compare the discrimination capacity against the most used risk stratification strategies derived from the 2015 ESC/ERS PH Guidelines: (1) COMPERA risk assessment strategy [patients were categorised as low, intermediate, or high risk by assigning a grade (low $=1$, intermediate $=2$, high $=3$ ) according to thresholds prescribed by the $2015 \mathrm{ESC} / \mathrm{ERS}$ guidelines to these variables: WHO FC, 6MWD, BNP or NT-pro-BNP, $\mathrm{RAP}, \mathrm{CI}$ and $\mathrm{SvO}_{2}$; the overall risk category is determined by computing the mean of the risk grades from available variables for each patient and rounding to the nearest integer] $^{14-16} ;(2)$ the FPHR strategy [WHO FC, 6MWD, RAP and CI were considered for each patient and risk is defined by how many low-risk values, according to thresholds prescribed by the 2015 ESC/ERS guidelines, are assigned to a patient; the FPHR methodology defined only the low risk group anyway, as suggested in previous works, we considered the presence of three or four lowrisk variables to be low risk, the presence of one or two low-risk variables to be intermediate risk, and no lowrisk variables to be high risk $].{ }^{26}$ Akaike's information criterion and Bayesian information criterion were also provided. The comparison with the REVEAL strategy was not performed because it considers also parameters that cannot be modified by PAH-specific treatment: for this reason, these parameters were not included in the 2015 ESC/ERS guidelines risk table, which is, instead, closely integrated with the therapeutic algorithm. Statistical analyses were performed using STATA/SE V.12.0 (StataCorp).

\section{Patient and public involvement}

Patients were not involved in designing or conduct of the study. 
Treatment-naïve patients (from 1 Feb 2003 to 31 Dec 2017)

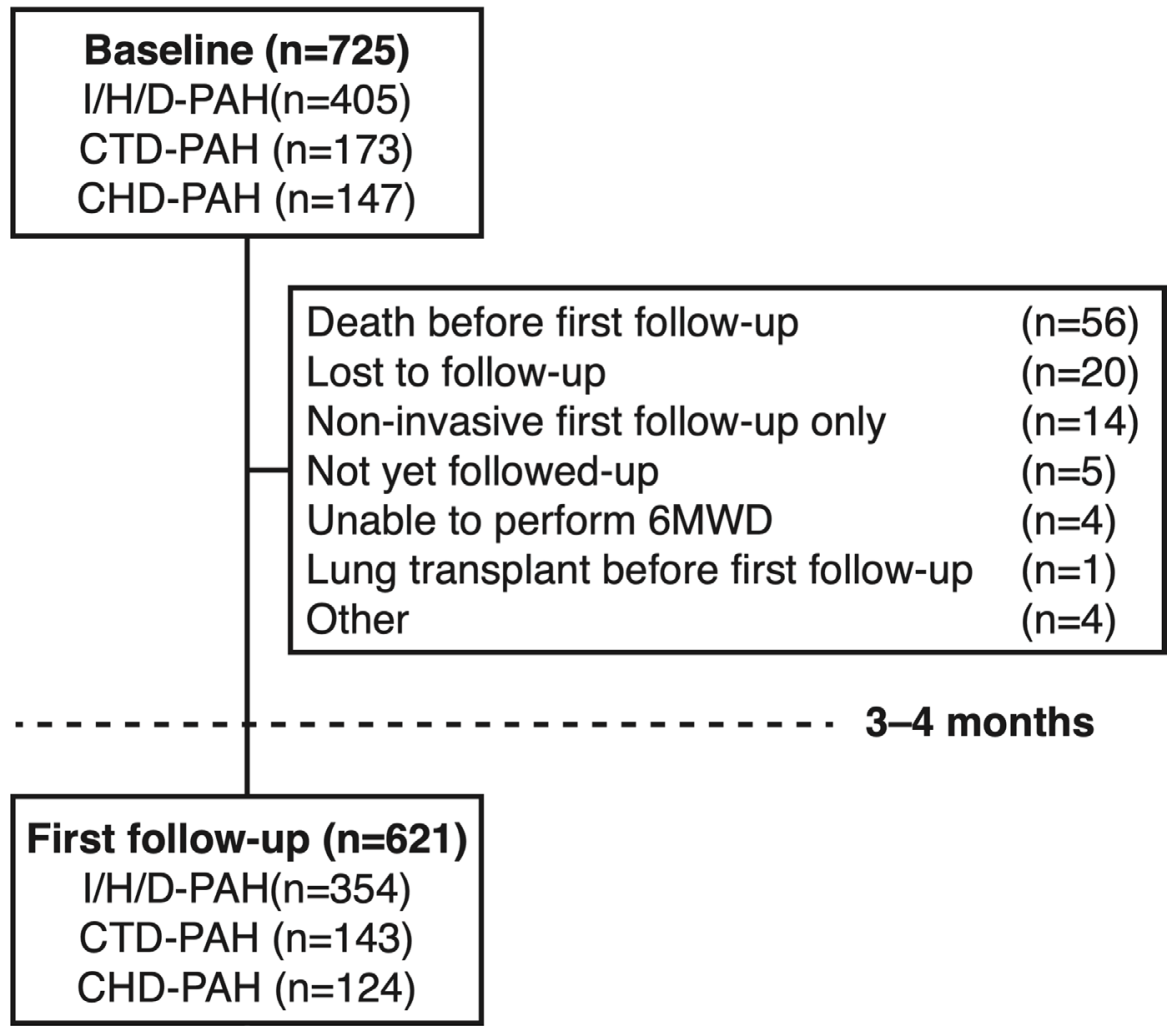

Figure 1 Patient disposition. 6MWD, 6 min walk distance; CHD, congenital heart disease; CTD, connective tissue disease; I/H/D, idiopathic/heritable/drug; $\mathrm{PAH}$, pulmonary arterial hypertension.

\section{RESULTS}

\section{Patients}

A total of 933 patients were eligible for inclusion, of which $725(77.7 \%)$ were treatment-naive and $208(22.3 \%)$ were previously treated (figure 1) at baseline. The median follow-up time was 4.4 years. The primary cohort in this analysis was the treatment-naive group whose characteristics are shown in table 2. The predictive value of each of the six parameters considered in the simplified risk table (table 1) in this primary cohort at baseline is shown in online supplemental figure 1.

Of the treatment-naive patients, $45.7 \%(\mathrm{n}=331)$ were classified as IPAH, 8.7\% $(\mathrm{n}=63)$ as HPAH, $1.5 \%(\mathrm{n}=11)$ as DPAH, 23.9\% ( $\mathrm{n}=173)$ as CTD-PAH, $20.2 \%(\mathrm{n}=147)$ as CHD-PAH. The main reasons for unavailability of patient data at first follow-up $(\mathrm{n}=104)$ were patient death $(\mathrm{n}=56)$ and lost to follow-up $(n=20)$ (figure 1). We also evaluated the cohort of previously treated patients and found they were similarly matched to the main cohort (online supplemental table 1) in regard to gender but they were younger and generally less impaired in regards to the percentage of patients categorised as WHO FC III-IV, to the exercise capacity and to the haemodynamic parameters.

Survival by risk category at baseline

At baseline, for the overall treatment-naive population, $18.8 \%, 60.7 \%$ and $20.5 \%$ of patients were in the lowrisk, intermediate-risk and high-risk groups, respectively.
Twelve-month survival for the low-risk, intermediaterisk and high-risk groups for the overall population was $100.0 \%, 92.3 \%$ and $74.8 \%$, respectively. Risk discrimination was similar to the COMPERA and the FPHR strategies (online supplemental table 2). Survival estimates at baseline for the overall treatment-naive population, and IPAH/HPAH/DPAH, CTD-PAH and CHD-PAH subgroups, showed a statistically significant difference $(\mathrm{p}<0.001)$ between the risk groups (figure 2$)$.

Pairwise comparisons in survival estimates between risk groups were also statistically significant in all cases with the exception of low-riskvs intermediate-risk groups in patients diagnosed with CHD-PAH (table 3 and online supplemental table 3 ).

In general, predicted survival at baseline was better for the IPAH/HPAH/DPAH and CHD-PAH subgroups than the CTD-PAH subgroup (figure 2).

Eleven patients $(1.5 \%)$ had three low-risk criteria but also either CI or $\mathrm{SvO}_{2}$ high-risk criterion. Five patients $(0.7 \%)$ had three low-risk criteria but also either RAP or NT-pro-BNP/BNP high-risk criterion. These two groups were designated as intermediate-risk group.

The previously treated population could also be differentiated into meaningful high-risk, intermediate-risk and low-risk groups (online supplemental figure 2). Twelvemonth survival for the low-risk, intermediate-risk and high-risk groups for the overall population was $100.0 \%$, 
Table 2 Baseline treatment-naive patient characteristics

\begin{tabular}{|c|c|c|c|c|}
\hline & All & IPAH/HPAH/DPAH & CTD-PAH & CHD-PAH \\
\hline $\mathrm{N},(\%)$ & $725(100)$ & $405(55.9)$ & $173(23.9)$ & $147(20.2)$ \\
\hline Male, n (\%) & $226(31)$ & $155(38)$ & $16(9)$ & $55(37)$ \\
\hline Age at diagnosis, years & $51(32-67)$ & $51(34-65)$ & $66(55-73)$ & $30(14-43)$ \\
\hline Age at $1^{\text {st }}$ Bologna evaluation, years & $53(36-67)$ & $51(35-65)$ & $66(55-73)$ & $38(26-52)$ \\
\hline Aetiology, n (\%) & & $\begin{array}{l}\text { IPAH } 331(82) \\
\text { HPAH } 63 \text { (15) } \\
\text { DPAH } 11(3)\end{array}$ & $\begin{array}{l}\text { SSc } 138 \text { (80) } \\
\text { Undiff/Mixed } 16 \text { (9) } \\
\text { SLE } 11 \text { (6) } \\
\text { Rheumatoid arthritis } 5(3) \\
\text { Sjögren's syndrome } 3 \text { (2) }\end{array}$ & $\begin{array}{l}\text { Eisenmenger } 86(59) \\
\text { Left-right shunt } 23(16) \\
\text { Small } 8(5) \\
\text { Corrected } 30(20)\end{array}$ \\
\hline WHO FC III-IV, n (\%) & $494(68)$ & $279(69)$ & $143(83)$ & $72(49)$ \\
\hline 6MWD, m & $\begin{array}{l}389(290-468) \\
n=686\end{array}$ & $\begin{array}{l}402(311-497) \\
n=394\end{array}$ & $\begin{array}{l}317(232-402) \\
n=152\end{array}$ & $\begin{array}{l}421(340-474) \\
n=140\end{array}$ \\
\hline $\mathrm{BNP}(\mathrm{ng} / \mathrm{L})$ & $\begin{array}{l}146(53-313) \\
n=72\end{array}$ & $\begin{array}{l}135(51-320) \\
n=43\end{array}$ & $\begin{array}{l}152(47-471) \\
n=24\end{array}$ & $\begin{array}{l}175(54-202) \\
n=5\end{array}$ \\
\hline NT-pro-BNP (ng/L) & $\begin{array}{l}807(268-2237) \\
n=332\end{array}$ & $\begin{array}{l}598(247-1810) \\
n=189\end{array}$ & $\begin{array}{l}1771(632-4054) \\
n=79\end{array}$ & $\begin{array}{l}720(187-1283) \\
n=64\end{array}$ \\
\hline RAP, $\mathrm{mm} \mathrm{Hg}$ & $7(4-10)$ & $7(4-10)$ & $7(4-12)$ & $6(4-9)$ \\
\hline mPAP, mm Hg & $53(42-64)$ & $52(42-62)$ & $46(38-55)$ & $69(51-83)$ \\
\hline PAWP, mm Hg & $8(6-10)$ & $8(6-10)$ & $8(6-10)$ & $9(7-11)$ \\
\hline $\mathrm{mBP}, \mathrm{mm} \mathrm{Hg}$ & 90 (82-99) & 90 (82-99) & $92(85-104)$ & $86(78-93)$ \\
\hline $\mathrm{Cl}, \mathrm{L} / \mathrm{min} / \mathrm{m}^{2}$ & $2.4(1.9-2.9)$ & $2.3(1.9-2.8)$ & $2.3(1.9-2.9)$ & $2.4(1.9-3.2)$ \\
\hline PVR, Wood units & $11(7-16)$ & $11(8-16)$ & $9(7-13)$ & $15(10-23)$ \\
\hline SVR, Wood units & $21(17-26)$ & $21(17-26)$ & $21(17-28)$ & $21(17-26)$ \\
\hline Art $0_{2}$ saturation, $\%$ & $95(92-97)$ & $95(93-97)$ & $95(93-97)$ & $90(83-95)$ \\
\hline $\mathrm{SvO}_{2}$ saturation, $\%$ & $65(57-71)$ & $64(57-70)$ & $63(54-69)$ & $70(64-76)$ \\
\hline
\end{tabular}

All non-percentage values are median $\left(25^{\text {th }}-75^{\text {th }}\right.$ percentile).

Art $\mathrm{O}_{2}$, arterial oxygen; BNP, brain natriuretic peptide; $\mathrm{CHD}$, congenital heart disease; $\mathrm{Cl}$, cardiac index; CTD, connective tissue disease; DPAH, drug-induced PAH; HPAH, heritable PAH; IPAH, idiopathic PAH; mBP, mean blood pressure; mPAP, mean pulmonary arterial pressure; 6MWD, 6 min walk distance; NT-pro-BNP, N-terminal probrain natriuretic peptide; PAH, pulmonary arterial hypertension; PAWP, pulmonary artery wedge pressure; PVR, pulmonary vascular resistanc; RAP, right atrial pressure; SLE, systemic lupus erythematosus; SSc, systemic sclerosis; $\mathrm{SvO}_{2}$, mixed venous oxygen saturation; SVR, systemic vascular resistance; WHO FC, WHO functional class.

$92.3 \%$ and $70.4 \%$, respectively. Risk discrimination was similar to the COMPERA and the FPHR strategies (online supplemental table 2).

\section{Survival by risk category at first follow-up}

For the overall treatment-naive population with data from a follow-up assessment $(\mathrm{n}=621), 44.1 \%$ were in the low-risk group, $49.8 \%$ in the intermediate-risk group and $6.1 \%$ in the high-risk group. Twelve-month survival for the low-risk, intermediate-risk and high-risk groups for the overall population was $98.5 \%, 88.3 \%$ and $76.1 \%$, respectively. Risk discrimination was similar to the COMPERA strategy and only slightly inferior to the FPHR strategy [c-statistic $=0.692(95 \%$ CI, 0.664 to 0.720 ) vs 0.716 ( $95 \% \mathrm{CI}, 0.686$ to 0.747 ); $\mathrm{p}=0.014$; online supplemental table 2]. The predicted survival estimates at first follow-up were similar in patterns to those seen at baseline, showing statistically significant differences $(p<0.001)$ between the risk groups in the overall population and in each sub group (figure 3). Pairwise comparisons in survival estimates between risk groups were also statistically significant in all cases with the exception of the comparison between intermediate-risk and high-risk groups in patients diagnosed with CTDPAH $(p=0.066)$ (table 3$)$. Nineteen patients $(3.1 \%)$ had three low-risk criteria but also either CI or $\mathrm{SvO}_{2}$ highrisk criterion and were designated as intermediate-risk group.

In a separate analysis, we evaluated the prognostic value of risk category at first follow-up taking into consideration the patients' baseline status. In the overall treatment group and the three subgroups, patients who remained in or improved to low-risk had a significantly better estimated survival compared with patients who remained in or worsened to intermediate or high risk ( $\mathrm{p} \leq 0.005$; figure 4$)$. In all populations, similar outcomes were observed for patients in the low-risk group at first follow-up irrespective of their status at baseline. Similarly, the prognosis for patients in intermediate/high-risk at follow-up was comparable between those 


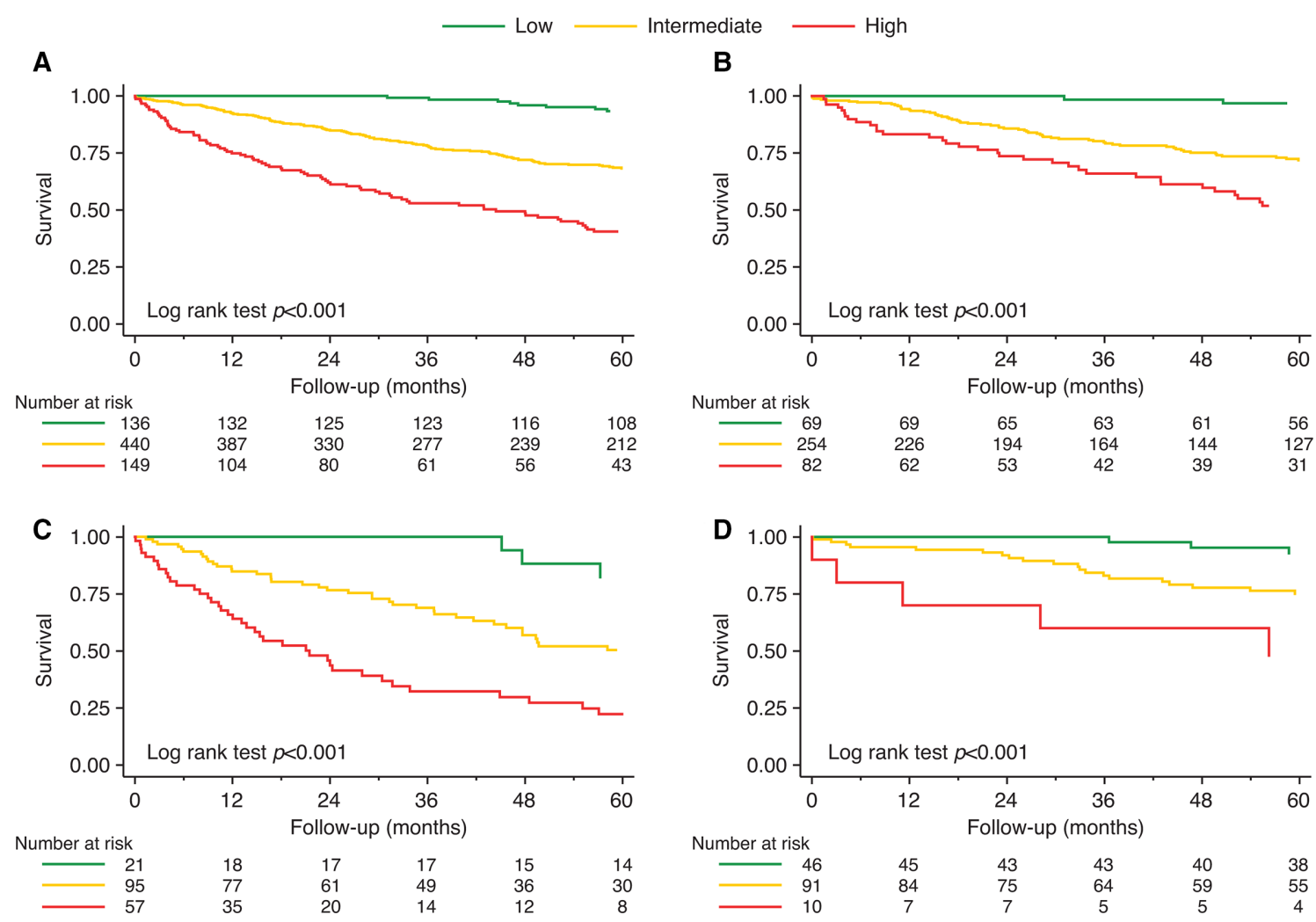

Figure 2 Risk stratification at baseline for (A) overall treatment-naive patient population, (B) IPAH/HPAH/DPAH, (C) CTD-PAH and (D) CHD-PAH subgroups. CHD, congenital heart disease; CTD, connective tissue disease; DPAH, drug-induced PAH; HPAH, heritable PAH; IPAH, idiopathic PAH; PAH, pulmonary arterial hypertension.

who remained in intermediate/high risk and those who worsened to intermediate/high risk.

\section{DISCUSSION}

Our data support the use of a risk assessment approach based on four criteria derived from up to six parameters outlined as prognostic variables for $\mathrm{PAH}$ in the 2015 ESC/ERS PH guidelines. The approach can discriminate between PAH patients at baseline and first follow-up and can do so in patients with CTD-PAH and CHD-PAH as well as IPAH patients. The intermediaterisk group appears to be the larger at both baseline and first follow-up and has a statistically different mortality as compared with low-risk and high-risk groups except in patients with CHD-PAH, where it tended to be closer to the low-risk group at baseline, and in patients with CTD$\mathrm{PAH}$, where it tended to be closer to the high-risk group at first follow-up. The predominance of the intermediaterisk group at baseline and first follow-up and the worse outcome as compared with the low-risk group has also been observed in the other registries studies. ${ }^{13-15}$ We also showed that the outcome of patients who improved to the low-risk category at first follow-up was similar to that of patients who remained in low-risk group from baseline. Similarly, patients who worsened to intermediate/ high risk had outcomes comparable to patients who were in the intermediate-risk/high-risk group at baseline and remain in intermediate-risk/high-risk group at first follow-up. The above points support the 2015 ESC/ERS $\mathrm{PH}$ guidelines recommendation to consider the low-risk

\begin{tabular}{|c|c|c|c|c|c|}
\hline & Risk-group comparison & All & IPAH/HPAH/DPAH & CTD-PAH & CHD-PAH \\
\hline \multirow[t]{3}{*}{ Baseline } & Low versus intermediate & $<0.001$ & $<0.001$ & 0.006 & 0.122 \\
\hline & Low versus high & $<0.001$ & $<0.001$ & $<0.001$ & $<0.001$ \\
\hline & Intermediate versus high & $<0.001$ & $<0.001$ & $<0.001$ & $<0.001$ \\
\hline \multirow[t]{3}{*}{ Follow-up } & Low versus intermediate & $<0.001$ & $<0.001$ & $<0.001$ & 0.012 \\
\hline & Low versus high & $<0.001$ & $<0.001$ & $<0.001$ & $<0.001$ \\
\hline & Intermediate versus high & $<0.001$ & 0.004 & 0.066 & $<0.001$ \\
\hline
\end{tabular}

CHD, congenital heart disease; CTD, connective tissue disease; DPAH, drug-induced PAH; HPAH, heritable PAH; IPAH, idiopathic PAH; PAH, pulmonary arterial hypertension. 


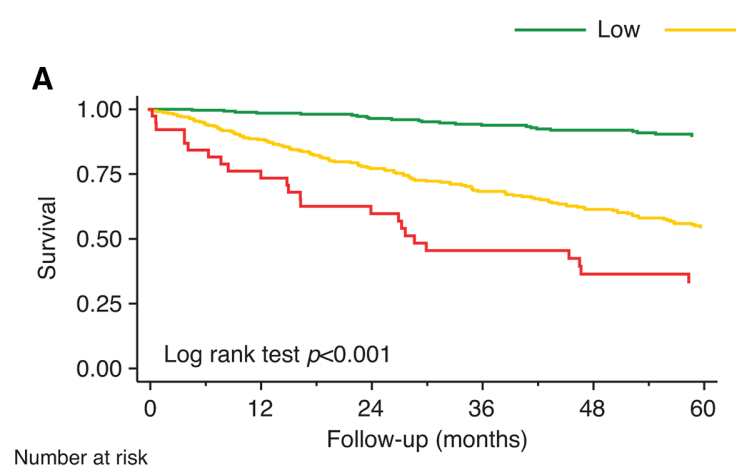

Intermediate $\longrightarrow$ High

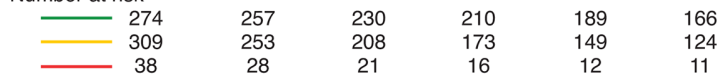

B

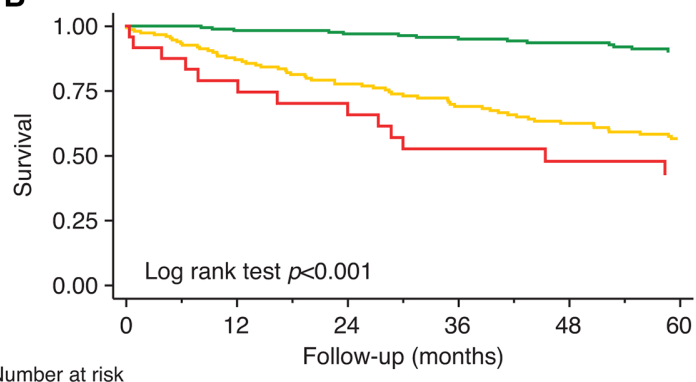

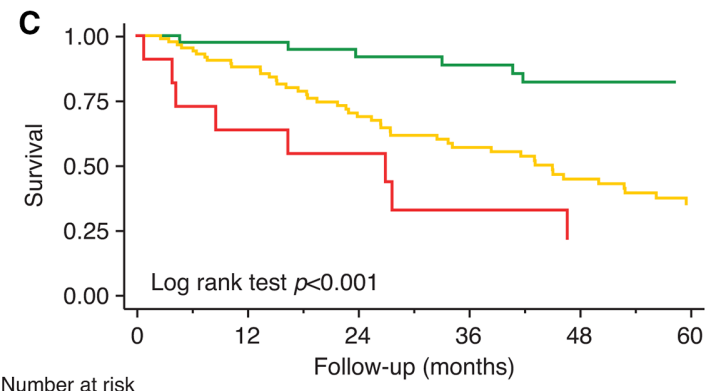

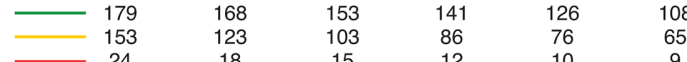

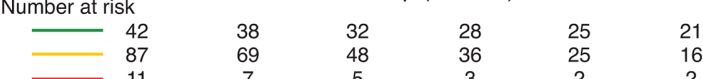

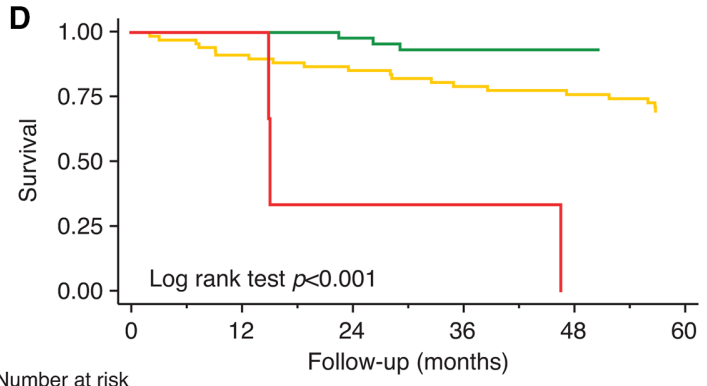

Number at risk

\begin{tabular}{|c|c|c|c|c|}
\hline 53 & 51 & 45 & 41 & 38 \\
\hline 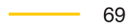 & 61 & 57 & 51 & 48 \\
\hline 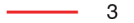 & 3 & 1 & 1 & 0 \\
\hline
\end{tabular}

Figure 3 Risk stratification at follow-up for (A) overall treatment-naive patient population, (B) IPAH/HPAH/DPAH, (C) CTDPAH and (D) CHD-PAH subgroups. CHD, congenital heart disease; CTD, connective tissue disease; DPAH, drug-induced PAH; HPAH, heritable PAH; IPAH, idiopathic PAH; PAH, pulmonary arterial hypertension.

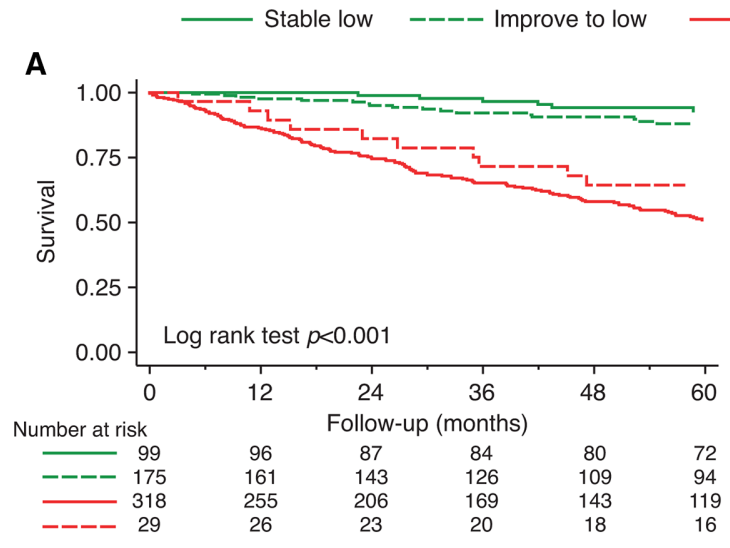

Stable inter-high $\quad----$ Worsen to inter-high
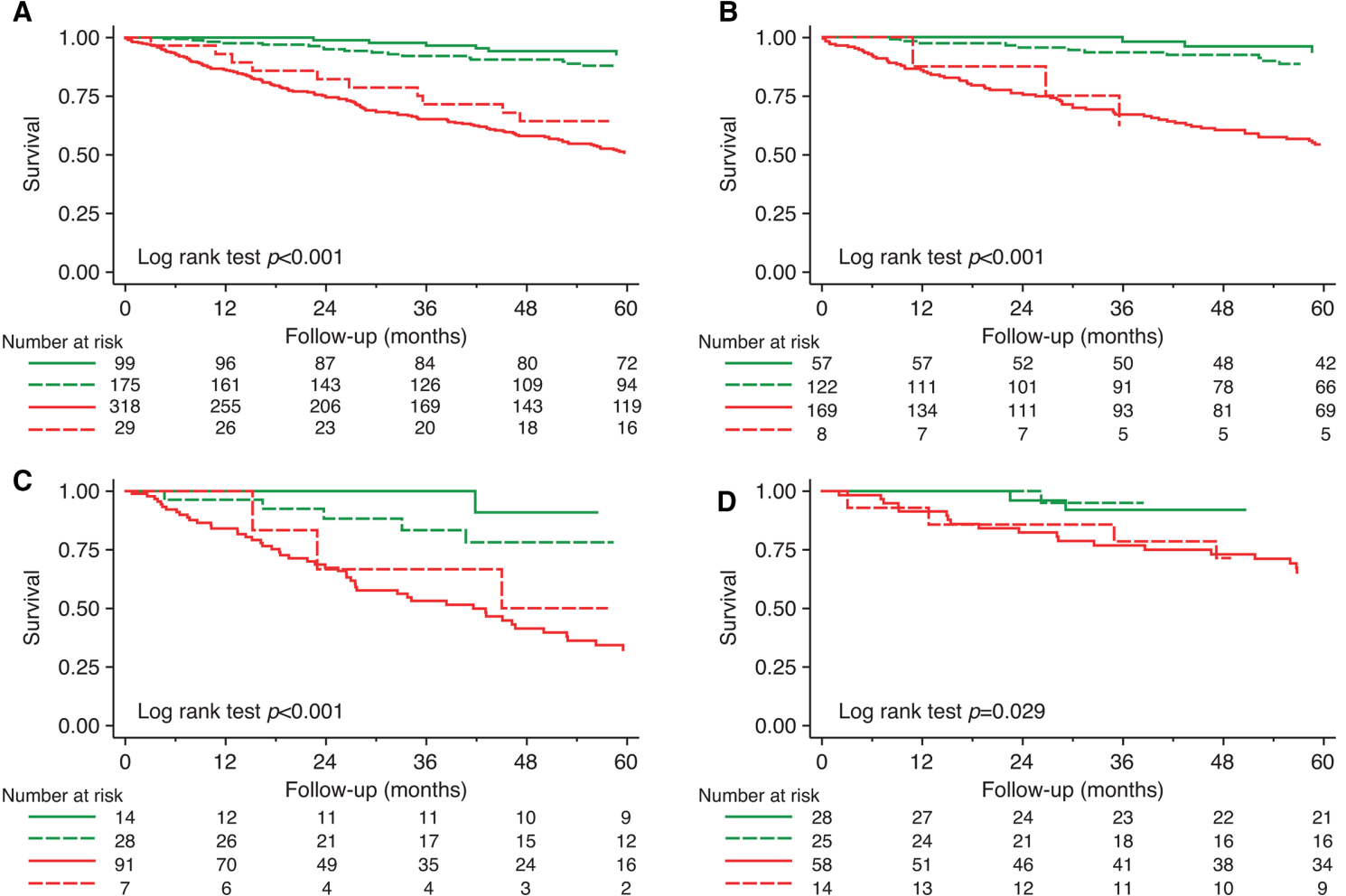

Figure 4 Change in risk stratification from baseline to follow-up for (A) overall treatment-naive patient population, (B) IPAH/ HPAH/DPAH, (C) CTD-PAH and (D) CHD-PAH subgroups. CHD, congenital heart disease; CTD, connective tissue disease; DPAH, drug-induced PAH; HPAH, heritable PAH; IPAH, idiopathic PAH; PAH, pulmonary arterial hypertension. 
profile as treatment goal for PAH patients and to implement treatment escalation in both intermediate-risk and high-risk groups in IPAH, CTD-PAH and CHD-PAH. In addition, this recommendation applies to both treatment naive and previously treated patients at baseline.

The simplified risk assessment performed in our study (table 1) allows a straightforward identification, at the patient's bedside, of low, intermediate and high risk without the need for a 'score and average method' requiring a calculator ${ }^{1415}$ or a low-risk oriented strategy that may miss the distinction between intermediate-risk and high-risk patients. In our study, as well as in other experiences, these two groups include the majority of the patients, have different mortality rates and may then require different treatment approaches as suggested in the 2015 ESC/ERS PH guidelines. The reduced number of parameters used for the proposed pragmatic risk assessment approach (table 1) may facilitate its implementation in clinical practice. In addition, grouping parameters that are pathophysiologically correlated such as NT-pro-BNP/BNP and RAP or CI and $\mathrm{SvO}_{2}$ provide flexibility and may avoid data redundancy or excessive influence of specific mechanisms on the risk-stratification assessment. Despite its simplicity our model has a risk discrimination similar to that of the COMPERA model and, moreover, the latter seems to overestimate mortality in intermediate risk patients in our registry both at baseline and at follow-up evaluation. Taking into account the comparison with the FPHR model it should be underlined that it was aimed at identifying only low-risk patients; anyway, if we arbitrarily define intermediate risk as the presence of one or two low-risk variables and high risk as the absence of low-risk variables included in the FPHR method, as done in previous works ${ }^{15}$ our model has a similar risk discrimination capacity at baseline evaluation in both treatment naive and previously-treated populations and only a slightly lower discrimination capacity at follow-up evaluation.

The proposed definition of low-risk patients in our simplified risk table (table 1) does not allow a pure noninvasive approach as proposed in other studies ${ }^{1317}$ due to the need to rule out all high-risk criteria including CI or $\mathrm{SvO}_{2}$. Interestingly, in our study, only approximately $2 \%$ and $3 \%$ of patients at baseline or first follow-up, respectively, could not be designated low-risk despite permissive WHO FC, 6MWD and NT-pro-BNP/BNP due to concurrent high-risk RAP or $\mathrm{CI}$ or $\mathrm{SvO}_{2}$. In accordance with these data, the non-invasive approach provides an acceptable accuracy in identifying the majority of low-risk patients. However, in specific cases such as young patients, the use of haemodynamic data may reinforce the reliability of the low-risk estimate and the distinction from intermediaterisk group, providing a better guidance for treatment decision making, in particular at the first follow-up. On the other side of the risk spectrum, the proposed highrisk definition (table 1), which by necessity includes the measurement of CI or $\mathrm{SvO}_{2}$, provides a clear distinction between intermediate- and high-risk groups which have a relevant difference in mortality (figures 2A and 3A). Our data suggest that haemodynamic data, having a relevant prognostic role (online supplemental figure 1), should always be collected at baseline and first follow-up, in particular in WHO FC III PAH patients to identify highrisk subjects requiring parenteral prostacyclin analogues as recommended by the 2015 ESC/ERS PH guidelines.

Our dataset is large enough to allow assessment of IPAH, CTD-PAH and CHD-PAH patients. Across the three aetiologies, all patients in the low-risk group show $100 \%$ survival, at baseline, and $>97 \%$ survival, at first follow-up, with 12-month Kaplan-Meier estimates in IPAH, CTD-PAH and in CHD-PAH patients. For the intermediate-risk and high-risk curves, we see that CTD-PAH patients appear to have reduced survival confirming a more refractory disease, as compared with the IPAH patients, and that the CHD-PAH patients have, as expected, better survival compared with the IPAH patients. In both the IPAH and CTD-PAH cohorts, the intermediate-risk groups' survival are closer to the high-risk group survival, while for the CHD-PAH population, the intermediate-risk group survival is closer to the low-risk group. This different behaviour of the intermediate-risk group survival across the three aetiologies may suggest a less aggressive treatment escalation in intermediate-risk CHD-PAH patients.

The first follow-up data showing the outcome of patients who remained in low risk from baseline versus those who improved to low risk, and the patients who remained in intermediate/high risk versus those who worsened to intermediate/high risk are extremely important. These data indicate the prognostic relevance of improving the risk category for our patients as well as preventing deterioration.

\section{Limitations}

The limitations of our simplified approach include the validation by retrospective analyses of a prospective registry as in all other studies on this topic.

Our complete data set included approximately 200 patients who were already receiving treatment when referred to our centre. While the analyses of these patients at baseline showed similar results, analyses at follow-up have not been included as we encountered significant heterogeneity in the timing of first follow-up assessments making interpretation of these data problematic.

We have not included our evaluation data from other investigations such as echocardiography, MRI and cardiopulmonary exercise test because they were not systematically assessed at both baseline and follow-up.

\section{CONCLUSIONS}

The simplified version of the 2015 ESC/ERS PH guidelines recommendation for risk assessment in PAH patients is able to discriminate into meaningful high-risk, intermediate-risk and low-risk groups in treatment-naive IPAH, CTD-PAH and CHD-PAH patients at baseline and first follow-up. The baseline evaluation appears to have 
prognostic relevance also in patients already treated with PAH medications. This pragmatic approach confirms the appropriateness of the low-risk profile as a treatment goal for PAH patients. The non-invasive strategy for low-risk designation seems to be accurate in up to $98 \%$ but not all cases. The proposed simplified risk stratification may facilitate the implementation of the risk-oriented treatment strategy of the 2015 ESC/ERS PH guidelines.

Acknowledgements Medical writing and editorial support was provided by Lisa Brackenbury and Richard McDonald of Watermeadow Medical, an Ashfield Company, funded by Actelion Pharmaceuticals. An early version of the work was presented at the American Heart Association Annual Scientific Sessions 2018 and American College of Cardiology Annual Scientific Sessions 2019.

Contributors Study design: FD and NG. Collection of data: FD, EZ, DG, ADL, IM, $M R, A B$ and GVLR. Data analysis: FD and GVLR. Statistical analysis: FD and EN. Drafting of the manuscript: FD, AM, NG and MP. Critical revision for important intellectual content: FD, AM and NG. Revision, editing and approval of the final manuscript: all authors. FD is responsible for the overall content as guarantor, accepts full responsibility for the finished work and/or the conduct of the study, has access to the data, and controlled the decision to publish.

Funding This work was supported by Department of Experimental, Diagnostic and Specialty Medicine-DIMES, University of Bologna, Bologna, Italy and by the National Institute of Biostructures and Biosystems, Rome, Italy.

Competing interests $F D, E Z, D G, A D L, I M, M R, E N, A B$ and GVLR have nothing to disclose. AM has received grants, personal fees and non-financial support from Actelion Pharmaceuticals. MP has received grants, personal fees and non-financial support from Actelion Pharmaceuticals. NG has received grants, personal fees and non-financial support from Actelion Pharmaceuticals, Bayer, GSK, MSD and Pfizer.

Patient consent for publication Not applicable.

Ethics approval Data from all consecutive patients with $\mathrm{PH}$ who were referred to the Pulmonary Vascular Disease Centre of the Bologna University are included in a prospective electronic registry (ARChivio elettronico ipertensione polmonAre; ARCA) approved by the Ethics Committee of the St. Orsola-Malpighi Hospital (109/2016/U /U/Oss)

Provenance and peer review Not commissioned; externally peer reviewed.

Data availability statement Data are available on reasonable request. All data relevant to the study are included in the article or uploaded as online supplemental information. All provided data included in the article cannot be traced back to individuals that participated in the study.

Open access This is an open access article distributed in accordance with the Creative Commons Attribution Non Commercial (CC BY-NC 4.0) license, which permits others to distribute, remix, adapt, build upon this work non-commercially, and license their derivative works on different terms, provided the original work is properly cited, appropriate credit is given, any changes made indicated, and the use is non-commercial. See: http://creativecommons.org/licenses/by-nc/4.0/.

ORCID iDs

Fabio Dardi http://orcid.org/0000-0001-9611-6021

Elena Nardi http://orcid.org/0000-0003-4245-912X

\section{REFERENCES}

1 Galie N, Humbert M, Vachiery JL. ESC/ERS guidelines for the diagnosis and treatment of pulmonary hypertension: the joint Task force for the diagnosis and treatment of pulmonary hypertension of the European Society of cardiology (ESC) and the European respiratory Society (ERS): endorsed by: association for European paediatric and congenital cardiology (AEPC), International Society for heart and lung transplantation (ISHLT). Eur Heart $J$ 2015;2016:67-119.

2 Galie N, Humbert M, Vachiery JL. ESC/ERS guidelines for the diagnosis and treatment of pulmonary hypertension: the joint Task force for the diagnosis and treatment of pulmonary hypertension of the European Society of cardiology (ESC) and the European respiratory Society (ERS): endorsed by: association for European paediatric and congenital cardiology (AEPC), International
Society for heart and lung transplantation (ISHLT). Eur Respir $J$ 2015;2015:903-75.

3 Galiè N, Palazzini M, Manes A. Pulmonary arterial hypertension: from the Kingdom of the near-dead to multiple clinical trial meta-analyses. Eur Heart J 2010;31:2080-6.

4 Lajoie AC, Lauzière G, Lega J-C, et al. Combination therapy versus monotherapy for pulmonary arterial hypertension: a meta-analysis. Lancet Respir Med 2016;4:291-305.

5 Humbert M, Sitbon O, Chaouat A, et al. Survival in patients with idiopathic, familial, and anorexigen-associated pulmonary arterial hypertension in the modern management era. Circulation 2010:122:156-63.

6 Benza RL, Miller DP, Gomberg-Maitland M, et al. Predicting survival in pulmonary arterial hypertension: insights from the registry to evaluate early and long-term pulmonary arterial hypertension disease management (reveal). Circulation 2010;122:164-72.

7 Benza RL, Gomberg-Maitland M, Miller DP, et al. The reveal registry risk score calculator in patients newly diagnosed with pulmonary arterial hypertension. Chest 2012;141:354-62.

8 Benza RL, Miller DP, Foreman AJ, et al. Prognostic implications of serial risk score assessments in patients with pulmonary arterial hypertension: a Registry to evaluate early and long-term pulmonary arterial hypertension disease management (reveal) analysis. $J$ Heart Lung Transplant 2015;34:356-61.

9 Frantz RP, Farber HW, Badesch DB, et al. Baseline and serial brain natriuretic peptide level predicts 5-year overall survival in patients with pulmonary arterial hypertension: data from the reveal registry. Chest 2018:154:126-35.

10 Galiè N, Jansa P, Pulido T, et al. SERAPHIN haemodynamic substudy: the effect of the dual endothelin receptor antagonist macitentan on haemodynamic parameters and NT-proBNP levels and their association with disease progression in patients with pulmonary arterial hypertension. Eur Heart J 2017;38:1147-55.

11 Souza R, Channick RN, Delcroix M, et al. Association between six-minute walk distance and long-term outcomes in patients with pulmonary arterial hypertension: data from the randomized SERAPHIN trial. PLoS One 2018;13:e0193226.

12 Chin KM, Rubin LJ, Channick R. Association of NT-proBNP and long-term outcome in pulmonary arterial hypertension (PAH): insights from the phase III GRIPHON study with selexipag. Am J Respir Crit Care Med 2018;197:A7585.

13 Boucly A, Weatherald J, Savale L, et al. Risk assessment, prognosis and guideline implementation in pulmonary arterial hypertension. Eur Respir J 2017;50. doi:10.1183/13993003.00889-2017. [Epub ahead of print: 0308 2017].

14 Hoeper MM, Kramer T, Pan Z, et al. Mortality in pulmonary arterial hypertension: prediction by the 2015 European pulmonary hypertension guidelines risk stratification model. Eur Respir J 2017;50. doi:10.1183/13993003.00740-2017. [Epub ahead of print: 0308 2017].

15 Kylhammar D, Kjellström B, Hjalmarsson C, et al. A comprehensive risk stratification at early follow-up determines prognosis in pulmonary arterial hypertension. Eur Heart $J$ 2018;39:4175-81.

16 Boucly A, Weatherald J, Chaouat A. Risk assessment in systemic sclerosis-associated pulmonary arterial hypertension. Am J Respir Crit Care Med 2018;197:A1178.

17 Hoeper MM, Pittrow D, Opitz C, et al. Risk assessment in pulmonary arterial hypertension. Eur Respir J 2018;51:1702606.

18 Galiè N, Torbicki A, Barst R, et al. Guidelines on diagnosis and treatment of pulmonary arterial hypertension. The task force on diagnosis and treatment of pulmonary arterial hypertension of the European Society of cardiology. Eur Heart J 2004;25:2243-78.

19 Galiè N, Hoeper MM, Humbert M, et al. Guidelines for the diagnosis and treatment of pulmonary hypertension: the task force for the diagnosis and treatment of pulmonary hypertension of the European Society of cardiology (ESC) and the European Respiratory Society (ERS), endorsed by the International Society of Heart and Lung Transplantation (ISHLT). Eur Heart J 2009;30:2493-537.

20 Galie N, Hoeper MM, Humbert M. Treatment of pulmonary hypertension of European Society of C, European respiratory S, International Society of $\mathrm{H}$, lung $\mathrm{T}$. guidelines for the diagnosis and treatment of pulmonary hypertension. Eur Respir J 2009;34:1219-63.

21 World Medical Association. World Medical Association Declaration of Helsinki: ethical principles for medical research involving human subjects. JAMA 2013;310:2191-4.

22 Dardi F, Manes A, Palazzini M, et al. Combining bosentan and sildenafil in pulmonary arterial hypertension patients failing monotherapy: real-world insights. Eur Respir J 2015;46:414-21.

23 Helgeson SA, Imam JS, Moss JE, et al. Comparison of brain natriuretic peptide levels to simultaneously obtained right heart hemodynamics in stable outpatients with pulmonary arterial 
hypertension. Diseases 2018;6. doi:10.3390/diseases6020033. [Epub ahead of print: 0105 2018].

24 Jain A, Shroff SG, Janicki JS, et al. Relation between mixed venous oxygen saturation and cardiac index. nonlinearity and normalization for oxygen uptake and hemoglobin. Chest 1991;99:1403-9.
25 McGoon MD, Benza RL, Escribano-Subias P, et al. Pulmonary arterial hypertension: epidemiology and registries. J Am Coll Cardiol 2013;62:D51-9.

26 Benza RL, Gomberg-Maitland M, Elliott CG, et al. Predicting survival in patients with pulmonary arterial hypertension: the reveal risk score calculator 2.0 and comparison with ESC/ERS-Based risk assessment strategies. Chest 2019;156:323-37. 